\title{
Imersão em jogos pervasivos ${ }^{1}$
}

Thaiane Moreira de Oliveira² 


\section{Resumo}

O objetivo deste trabalho é refletir acerca dos processos imersivos em jogos pervasivos, sobretudo, os jogos de realidade alternada, nos quais o transbordamento entre realidades e ficcionalidade permite uma experiência coletiva calcada pelo fingimento partilhado. Desta forma, busca-se compreender quais são as subjetividades implicadas nas interações em jogos pervasivos, tendo em vista que tais gêneros de jogos não estão restritos à utilização de apenas um único suporte midiático. Eles possuem uma temporalidade própria, para além da temporalidade comum dos sujeitos interatores e os jogadores, enquanto indivíduos, são interdependentes da coletividade para a vivência da experiência imersiva.

\section{Palavras-chave}

Estéticas, games studies, jogos pervasivos, imersão.

\section{Abstract}

The objective of this paper is to reflect about the immersive processes in pervasive games, especially, Alternate reality games, in which the overflow between realities and fictionality allows a collective experience grounded by shared pretending. We try to understand what are the subjectivities involved in interactions in pervasive games, considering that such genre of games is not restricted to the use of just a single media. They have their own temporality that goes beyond the usual temporality of the interactor subjects and players as individuals. They are interdependent of collectiveness in order to be able to live the immersive experience.

\section{Keywords}

Aesthetics, games studies, pervasive games, immersion. 
No capitalismo tardio, vemos uma proliferação da ficcionalização da realidade, da capturas do real em imagens que buscam apresentar estéticas realistas simulando ou cristalizando a vida cotidiana. São produções midiáticas que nos cercam e nos proporcionam uma pedagogia do realismo (JAGUARIBE, 2010) a fim de legitimar suas ficções enquanto retratos da realidade. Diferente do realismo literário do século XIX, nos quais as ficcções buscavam a verossilhança com a realidade através de métodos e recursos linguisticos peculiares, esta atual busca pelo real no ficcional implica em um outro movimento: utilizar elementos do real na composição do ficcional. Contudo, essa noção de real já não possui a mesma essência de antes, visto que ele já está contagiado pela ficcionalização de si e que, para ser reconhecido como tal, é necessária sua representação através de recuros midiátcos (SIBILIA, 2008). Esta fluidez de fronteiras que demarcam a realidade da ficcionalidade é uma caracteristica da sociedade contemporanea, marcada pelo gosto, pela afetação diante de simulacros e pelas simulações de espetacularizações do hiper-realismo moderno (ECO, 1984; LIPOVETSKY, SERROY, 2009).

Porém, mais do que apreensões da realidade, alguns gêneros de produções midiáticas utilizam-se desta estética não apenas para ficcionalizar o real, mas também para complementar a ficção na composição da obra. Uma dessas produções midiáticas são os Alternate reality games (ARG), considerado um gênero que transita e borra as fronteiras fluidas entre a realidade e a ficcionalidade.

Originados da experiência do Role Playing Games, os ARG são considerados uma subcategoria dos jogos pervasivos ou, segundo Jane McGonigal (2006), ubiquitous games. São um gênero de game que busca transcender suas ações para além do suporte mediador material entre o jogador e o programa, explorando tanto os espaços virtuais eletrônicos, quanto os espaços físicos urbanos da realidade concreta ${ }^{3}$.

3 Como a distinção entre os conceitos de pervasivos e ubiquitous ainda não se tornou senso comum, preferimos adotálos como sinônimos, utilizando apenas o termo pervasive para nos referir a este gênero de jogo que transborda seus elementos para o mundo comum. 
É um tipo de jogo que tem como eixo uma narrativa central fragmentada e que tende a utilizar, além da internet, diversas plataformas e dispositivos. Utiliza inclusive o próprio espaço urbano para distribuição dos puzzles e enigmas do jogo, conferindo seu caráter transmidiático ao objeto. Sua estrutura envolve diferentes ferramentas de comunicação - e-mails, mídias sociais, SMS, websites, telefonia móvel etc. -, utilizadas para conectar, em um universo ficcional, jogadores e personagens interpretados por atores. Em tal universo, o público deve resolver quebra-cabeças, investigar mistérios, dentre outros desafios, para avançar na narrativa transmidiática que dispersa os elementos em diversos canais (OLIVEIRA \& ANDRADE, 2010).

Com uma narrativa multilinear complexificada, os ARG exigem do jogador uma multiplicidade cognitiva baseada em compartilhamento social e informacional de descobertas (OLIVEIRA, 2011). O compartilhamento faz parte da lógica da visibilidade inerente à hiper-realidade, ou seja, ele só ocorre, enquanto fenômeno necessário ao jogo, se este é visto pelos seus pares.

Tendo como premissa fundamental o TINAG (This is not a game), os jogadores fingem que não é um jogo a fim de uma maximização da sua experiência no processo de jogar os Alternate reality games. A este fenômeno de "fingimento", Jane McGonigal (2003) chama de "efeito Pinóquio", no qual os jogadores suspendem voluntariamente sua descrença, não se importando com a inserção de elementos não diegéticos ao jogo. A autora afirma que este fingimento é uma decisão consciente para prolongar os prazeres da experiência. $\mathrm{O}$ fingimento ativo de crença propicia oportunidades de participação e colaboração, ignorando todos os elementos metacomunicacionais que poderiam indicar as fronteiras físicas, temporais e sociais do que é jogo. Neste caso, a sigla TINAG é um lembrete fácil para demarcar as fronteiras entre o que é realidade e ficção, durante a experiência, refletindo o envolvimento ou a imersão dos jogadores no universo diegético criado pelos ARG. Contudo, dentro desta experiência, os jogadores estruturam regras sociais dinâmicas próprias que os mantém seguros às noções de suas próprias realidades, pois, caso contrário, a sua imersão os 
condicionaria a um "afogamento" na diegese. Nas palavras de Marie-Laure Ryan, "o oceano é um ambiente em que não podemos respirar; para sobreviver à imersão, devemos levar oxigênio a partir da superfície, ficar em contato com a realidade" (RYAN, 2001, p. 97).

Diante das considerações aqui apresentadas, este artigo busca aprofundar as reflexões sobre o efeito imersivo nestes ambientes pervasivos, gerados a partir da estética realista explorada nos Alternate reality games. Busca-se, ainda, compreender quais são as subjetividades implicadas e transformadas pela suspensão voluntária da descrença (MCGONIGAL, 2003), que ocorre através da utilização de elementos e códigos hermenêuticos ontológicos (BARTHES, 1992; LONG, 2000), e pela criação ativa da crença (MURRAY, 2003) a partir de regras sociais dinâmicas estabelecidas e ajustadas durante o jogo.

\section{Imersividade versus e pervasividade em Jogos de Realidade Alternada}

Paula Sibilia, em seu livro O show do eu, discorre que, diante dos "abalos da ficção" na contemporaneidade, proveniente de um excesso informacional, uma das principais estratégias utilizadas pelos escritores literários a fim de conquistar seu público é recorrer a uma estética do real. Diante desta crescente utilização da estética realista em inúmeras obras, Sibilia afirma que "para tentar se aproximar dessa imersão tão absorvente que talvez tenha se perdido para sempre, um dos caminhos mais transitados pelos escritores contemporâneos consiste em recorrer à não-ficção" (SIBILIA, 2008, p. 220, grifo nosso). Contudo, resta-nos compreender que tipo de imersão é esta e quais são as implicações provenientes dos processos imersivos diante desta estética peculiar.

Entendemos o conceito de imersividade como a capacidade de um sistema em trazer seus usuários para outra dimensão do real por ele apresentada (COUCHOT, 2003, p. 175). O conceito de imersão atravessa vários campos, como a literatura, o cinema, as artes visuais e, a partir da segunda metade do século XX, a realidade virtual. Para Arlindo Machado (2002), existem dois 
tipos de imersividade: através do ponto de vista de um observador, com representação do interator no interior da cena, ou através de um ponto de vista interno, pelo efeito de câmera subjetiva. Contudo, o processo de imersão, assim apresentado, ocupa um lugar muito raso na discussão sobre o conceito e que precisa ser aprofundado. Entender esta imersão que leva o interator (jogador/ espectador/leitor/usuário) a outra dimensão dentro da diegese da obra é algo instigante, de interesse para diversas áreas e que precisa de uma pesquisa que articule diferentes campos do conhecimento. Sendo assim, o objeto a que está centrado este artigo são os jogos pervasivos, principalmente os Jogos de Realidade Alternada, que têm como premissa a utilização de estética do real para transbordar as fronteiras entre realidade e ficção. Os Alternate reality games são um gênero de jogo que transita entre as fronteiras da realidade e da ficcionalidade através de enigmas que ocupam tanto os espaços virtuais como também os espaços urbanos.

Dan Provost (2008) considera os ARG como a primeira forma de arte narrativa metaficcional nativa para a internet, que "borra" a linha tênue entre a ficção e a realidade e frequentemente requer, por sua complexidade, o uso de inteligência coletiva para resolver os enigmas que são projetados. O autor aponta que o aspecto mais atraente dos ARG é sua natureza comunitária, já que os puzzles são muito difíceis de serem resolvidos individualmente, e, portanto, exigem trabalho em equipe. Outra característica que exige um trabalho de inteligência coletiva é a narrativa fragmentada. Cabe ao jogador criar um significado coeso aos elementos dispersos que correspondem e respeitam a temporalidade do próprio jogador (MONTOLA; STENROS; WAERN, 2009), o que acontece em tempo real e não pode ser repetido. Assim, com uma narrativa multilinear complexificada, os ARG exigem do jogador uma multiplicidade cognitiva baseada em compartilhamento social e informacional de descobertas (OLIVEIRA, 2011).

Os ARG surgiram como gênero de jogo em 2001, com a campanha promocional do filme Inteligência Artificial, de Steven Spielberg. Este jogo 
recebeu o nome de The Beast, pelo fato de se especular que havia 666 enigmas presentes no game. Para tal jogo, havia três pontos de entrada, chamados de rabbit holes, ou buracos de coelho, em sua tradução, aludindo ao livro Alice no país das maravilhas, de Lewis Carrol, pseudônimo de Charles Lutwidge Dodgson. O rabbit hole se refere à estratégia utilizada pelos puppetmasters ${ }^{4}$ para fisgar o seu público-alvo de maneira que a realidade e a ficcionalidade se tornam fluidas. Para tanto, é de uso comum apropriar-se de estéticas realistas a fim de que a transitoriedade entre tais fronteiras ocorra de forma a não atrapalhar a diegese do jogo.

A estética do real não é um artifício utilizado apenas nos dias atuais ou nestes gêneros de jogos pervasivos. A literatura realista do século XIX demonstra que a captação do real através de recursos estéticos buscava suspender as descrenças dos leitores através de relatos descritíveis calcados na verossimilhança ficcional. Utilizando um "efeito de real", tal como Roland Barthes ([1968], 2004) articula, em sua obra O rumor da língua, em capítulo destinado à compreensão dos modos de subjetivação estéticos de verossimilhança com a realidade, tais obras buscavam articular uma representação descritiva da realidade. Analisando a obra de Gustave Flaubert, Barthes defende que a utilização de recursos baseados em detalhamento de ambientação é crucial para conferir à obra o aspecto de realidade. Contudo, a estética realista literária dos romances do século XIX possui diferenças significantes sobre os modos de subjetivação contemporâneos, através dos quais "o efeito de real" está implicado em uma espetacularização do sujeito e uma ficcionalização da vida cotidiana (SIBILIA, 2008; FELDMAN, 2008; JAGUARIBE, 2010). Isso confere a eles um alto grau persuasivo, visto que estão sedimentados em percepções naturalizadas, como funções interpretativas da realidade, através da instauração de uma pedagogia própria: a "pedagogia da realidade": 
Por 'pedagogia da realidade' compreendo o uso de estéticas realistas em várias modalidades e expressões como meio de ilustrar retratos da realidade contemporânea de uma forma legível para espectadores ou leitores. Trata-se de uma pedagogia porque estes registros oferecem pautas interpretativas permeadas pelo sentido comum de problemas cotidianos compartilhados (JAGUARIBE, 2010, p.7).

B. Jaguaribe ainda aponta que estas pedagogias da realidade não são homogêneas, visto que as realidades são socialmente fragmentadas. Baseandonos neste pensamento, defendemos que é possível identificar, apesar da heterogeneidade de tais pedagogias, os códigos utilizados para a instauração da estética realista na contemporaneidade e que fazem com que as fronteiras entre realidade e ficcionalidade se tornem fluidas. Para tanto, adotaremos a perspectiva de Geoffrey Long (2000), a partir do conceito dos códigos hermenêuticos de Roland Barthes (1992), para compreender os recursos estéticos utilizados que permitem a transitoriedade entre fiç̧ão e não fiç̧ão.

Em $S / Z$, Roland Barthes identifica cinco elementos que, num texto, introduzem um espaço de significação a ser percorrido ao longo do objeto. Chamando-os de códigos e campos, Barthes apresenta, em uma análise estrutural do texto Sarrasine, de Honoré de Balzac, os seguintes elementos: códigos das ações narrativas, código propriamente semântico, códigos culturais, código hermenêutico e campo simbólico.

Para R. Barthes, os códigos hermenêuticos e os de ações narrativas são irreversíveis e juntos estabelecem uma ordem lógico-temporal que conduz a própria narrativa (BARTHES, 1992, p. 89). Os códigos hermenêuticos são todas as unidades que podem "constituir um enigma e levar à sua solução" (BARTHES, 1992, p. 17). Os códigos de ações narrativas referem-se à capacidade de determinar racionalmente o resultado de um encadeamento.

Já os códigos semânticos e o campo simbólico são reversíveis e complementam a narrativa. O código semântico designa significantes aos significados instáveis e permite o desenvolvimento de um tema ao longo da 
narrativa, enquanto o campo simbólico são elementos conotativos que não podem ser representado diretamente no texto. Os códigos culturais de Barthes se referem a um "conjunto de referências, o saber geral de uma época sobre a qual se apoia o discurso" (BARTHES, 1992, p. 88).

Com base nesta classificação de R. Barthes, Geoffrey Long propõe a expansão de novas categorias para os códigos hermenêuticos. O autor sugere seis classificações possíveis, porém não únicas, de códigos hermenêuticos. São eles: culturais, de personagem, cronológica, geográficos, ambientais e ontológicos.

Long define códigos hermenêuticos culturais como elementos que se referem a uma cultura maior dentro do próprio universo diegético da narrativa. Códigos hermenêuticos de personagens são personagens e/ou motivações ou características de personagens que não aparecem na trama, mas são referenciados. Códigos hermenêuticos cronológicos são preocupações lógicotemporais da narrativa. Códigos hermenêuticos geográficos são elementos importantes que indicam ou remetem a lugares "que, ou não aparecem na história principal, ou só aparecem por alguns instantes" (LONG, 2000, p. 64, tradução nossa) ${ }^{5}$. Códigos hermenêuticos ambientais são construções do mundo ficcional que funcionam como ganchos para histórias adicionais. Diferem-se dos geográficos, pois estes não precisam aparecer na história, podendo haver uma sobreposição entre eles. E para se pensar a transitoriedade entre realidade e ficcionalidade, o principal é o código hermenêutico ontológico, considerado pelo autor como o mais raro entre os códigos de sua classificação, pois tem a capacidade de fazer o público refletir "sobre a própria natureza existencial da história que se está consumindo" (LONG, 2000, p. 65, tradução nossa) ${ }^{6}$. Logicamente que ambos os autores se valeram destas conceituações para investigação sobre o campo narrativo. Contudo, tais categorias podem ser ampliadas para a compreensão estética não apenas restrita à narrativa de uma

5 "(...) that either don't appear in the main story or appear only briefly" (LONG, 2000, p. 64).

6 "(...) about the very existential nature of the story they're consuming" (LONG, 2000, p. 65). 
obra, independente de seu meio. É possível identificar a utilização destes aportes conceituais para verificar os códigos utilizados nas estéticas dos sites oriundos das peças que compõem o jogo, assim como nos outros canais de comunicação, vídeos, blogs e etc.

Defendemos, aqui, que a utilização de tais códigos hermenêuticos é crucial para propiciar a imersão do jogador neste gênero de jogo. Por imersão, compreendemos o fenômeno que implica a criação ilusória de adentramento ao círculo mágico da diegese da narrativa. Por círculo mágico, tomamos, com base na conceituação de Johan Huizinga, a premissa de que os jogos possuem um universo espacial e temporal próprio que delimita as fronteiras do mundo do jogo e do mundo comum ou, como define Jesper Juul (2003) em relação ao ambiente da realidade concreta, o resto do mundo. Aprimorando a concepção de J. Huizinga (1980), Katie Salen e Eric Zimmerman (2003) utilizam a concepção de círculo mágico para refleti-la sobre domínios específicos que separam as raias do que é ordinário e do que é jogo.

Aplicando o conceito de círculo mágico para os jogos pervasivos, Eva Nieuwdorp (2005) argumenta que neste gênero de jogo é criada uma membrana permeável através da qual os elementos do game deslizam para o mundo real. $\mathrm{A}$ visão dicotômica entre o que é ordinário e o que é jogo parece não compreender uma variedade de operações cognitivas que medeiam a transição do jogador no mundo do jogo e no resto do mundo. Tal consideração é formulada por Emmanoel Ferreira e Thiago Falcão, que buscam apresentar estas fronteiras entre o que é jogo e o que não pertence ao seu universo como fluidas e fazendo parte de uma configuração cognitiva implicada no processo de imersão do jogador. 
pode ser apresentada tanto como uma forma fluida - desenhando fronteiras borradas, no sentido de que elas não podem ser claramente identificadas, as quais permitem que ficção e realidade se encontrem; e em uma forma mais definida - sólida que realmente permite o sentido do deslocamento - a supressão do espaço-tempo - através de um processo de imersão (FERREIRA; FALCÃo, 2009, p. 2, tradução nossa)7.

E. Ferreira e T. Falcão partem da premissa de que a imersão está intimamente ligada à atenção. Desta maneira, os autores categorizam dois tipos de imersividade atentiva: operacional e narrativa. A imersão operacional diz respeito à atenção seletiva, ou seja, ativada nos momentos em que o gameplay requer um nível de concentração para a solução imediata de tarefas específicas dentro de um curto espaço de tempo. Já a imersão narrativa, relacionada à atenção sustentada ou também chamada de vigilância, é quando a narrativa está atuando no primeiro plano do jogo e, desta maneira, o interator pode se dar ao prazer de navegar nos ambientes, observando elementos mais amplos que não são captados no modo de imersão operacional. E. Ferreira e T. Falcão ainda defendem que "o círculo mágico, por meio de controle da atenção, administra a relação entre o jogador e o jogo, em uma escala gradual entre menos imerso e mais imerso no jogo (e, respectivamente, mais ou menos "presente na vida real 'fora' do jogo" (FERREIRA \& FALCÃO, 2009, p.7 - tradução nossa) ${ }^{8}$.

Certamente esta categorização defendida pelos autores não é aplicável totalmente aos ARG, já que a narrativa ocupa o papel de centralidade neste gênero de jogo, não havendo alternância entre narrativa e operacionalidade como em jogos estritamente eletrônicos. Contudo, torna-se interessante a

$7 \quad$ "Thus, the point would not be to consider the magic circle as something that necessarily encapsulates the player, suppressing space-time and projecting her into an alternative zone. Instead, we would acknowledge the existence of the magic circle - alongside with its inherence to the game structure - but as a mediation element, which facilitates the player dialogue to both the game space and the reality. Such mediation may be presented both as a fluid form - drawing blurred borders, in the sense that they cannot be plainly identified, which allows fiction and reality to meet; and in a harder, more defined - solid - form, which really enables the sense of displacement - space-time suppression - through an immersive process (FERREIRA; FALCÃO, 2009, p. 2)".

8 The magic circle, through attentional control, manages the relation between player and game, in a gradual scale between less immersed and more immersed in the game (and respectively more or less 'present' in real life, 'outside' the game)" (FERREIRA \& FALCÃO, 2009, p. 7). 
proposta de que o círculo mágico seja controlado gradualmente, em um processo cognitivo, para a transição do jogador entre o ingame e o outgame. Isso não apenas para compreender e refletir sobre o processo imersivo dos jogos de realidade alternada, mas também de uma gama de gêneros de jogos.

E. Brown e P. Cairns (2004) compreendem a imersão como grau de envolvimento com o jogo que varia conforme os graus de atenção e envolvimento com o mesmo. Para os autores, existem três níveis de imersão: o engajamento, a absorção e a imersão total. No primeiro nível, os jogadores requerem um investimento de tempo e atenção para domínio do funcionamento do game. No nível da absorção, os jogadores apresentam um envolvimento emocional, enquanto no terceiro nível apresentado pelos autores, o de imersão total, o jogo é o único elemento importante para o jogador que desenvolve uma empatia com os personagens e com a atmosfera virtual.

Como os efeitos imersivos em ARG necessitam de um estudo mais aprofundado com base em dados empíricos, fica superficial tentar determinar os graus de imersão neste gênero de jogo a partir da visão triádica de E. Brown e P. Cairn. Contudo, é possível perceber preliminarmente que esta imersão varia conforme o envolvimento do jogador no jogo. Há ainda outra perspectiva sobre os efeitos imersivos, a partir da abordagem de Laura Ermi e Frans Mäyrä, principalmente relacionada a jogos de RPG, que cunham de "imersão imaginativa":

Chamamos esta dimensão de experiência de jogo em que a pessoa se torna absorvida com as histórias e com o mundo, ou começa a se sentir ou se identificar com um personagem do jogo, de imersão imaginativa. Esta é a área na qual o jogo oferece ao jogador a chance de usar sua imaginação, criar empatia com os personagens, ou simplesmente desfrutar da fantasia do jogo (ERMI; MÄYRÄ, 2005, p. 8 - tradução nossa) ${ }^{9}$.

9 We call this dimension of game experience in which one becomes absorbed with the stories and the world, or begins to feel for or identify with a game character, imaginative immersion. This is the area in which the game offers the player a chance to use her imagination, empathise with the characters, or just enjoy the fantasy of the game" (ERMI; MÄYRÄ, 2005, p. 8). 
Para os autores, jogos com personagens e enredos onde os jogadores têm mais possibilidades de se identificarem com algo são mais capazes de propiciar a imersão imaginativa. Já Dominic Arsenault (2005) propõe uma releitura sobre o modelo estruturado por Laura Ermi e Frans Mäyrä, trocando o conceito de imersão imaginativa por imersão ficcional. Para o autor, a imersão imaginativa seria muito ampla e estaria condicionada à imersão ficcional.

Decerto, ambas as conceituações são interessantes para se pensar os ARG. A imersão ficcional de D. Arsenault nos dá a compreensão da relação entre o ficcional e o real inerente ao próprio jogo, enquanto a imersão imaginativa seria basilar no processo de se jogar um ARG. Ou ainda, qualquer outro gênero de jogo cujo gameplay se dê por meio de representação de personagens, através da qual a identificação dos papeis, juntamente com o processo mental de imaginação, sejam parte do "fingimento", de não ser um jogo, para uma maximização de suas experiências.

\section{TINAG e processos de subjetivação}

O fenômeno de fingimento presente nos ARG é chamado de TINAG (This is not a game), que demarca as fronteiras entre o que é realidade e ficção durante a experiência, refletindo o envolvimento ou a imersão dos jogadores no universo criado pelo Jogo de Realidade Alternada.

Partindo do princípio de que o TINAG só ocorre através da utilização de códigos hermenêuticos ontológicos que possibilitam a diluição das fronteiras da realidade e da ficcionalidade, é possível compreender que tais novas estéticas, utilizadas nos ARG, não exigem o mesmo tipo de suspensão da descrença que o realismo literário do século XIX. Estas estéticas contemporâneas se apoiam na representação da realidade naturalizada, camuflando os próprios mecanismos de ficcionalização (JAGUARIBE, 2010, p. 9).

Apesar do domínio sobre os códigos hermenêuticos ontológicos presentes nas peças do jogo, os jogadores buscam constantemente estar em contato com 
a realidade a fim de que a imersão não os condicione a um "afogamento" na diegese. Nesse período de jogo, que pode durar até meses, o contato gradual com o círculo mágico fica subordinado à temporalidade do "mundo ordinário" (JULL, 2003). O mundo do jogo necessita da participação coletiva para seu funcionamento, com regras dinâmicas próprias compartilhadas nas comunidades destinadas a este fim. Desta forma, o sujeito perde sua autonomia, mas não deixa de ter sua individualidade e seu livre arbítrio, para depender da coletividade na vivência de uma experiência em comum.

A suspensão da descrença é uma subjetividade implicada no individuo, porém para que esta ocorra, depende da coletividade. Partindo desta ideia é possível inferir que novos processos de subjetivação ocorrem na experiência de jogo. Compreendendo a subjetividade como sendo processos de formação social do sujeito, busca-se investigar quais seriam tais processos de subjetivação envolvidos neste gênero de jogo. Trazendo Félix Guattari como ponto de partida para a formulação:

O que importa aqui não é unicamente o confronto com uma nova matéria de expressão, é a constituição de complexos de subjetivação: indivíduogrupo-máquina-trocas múltiplas, que oferecem à pessoa possibilidades diversificadas de recompor uma corporeidade existencial, de sair de seus impasses repetitivos e, de alguma forma, de se re-singularizar (GUATTARI, 1992, p. 13).

Neste processo de re-singularização do indivíduo, trazendo para o objeto de estudo em questão, compreendemos os modos de objetivação que transformam os seres humanos em sujeitos (DELEUZE, 1992). Ou seja, o indivíduo jogador, ao interpretar a si mesmo na narrativa do jogo, reinventa-se enquanto sujeito, em uma capacidade de autopoiese (MATURANA; VARELA, 1992) dentro do meio de interação social. Compreendendo tais formações de subjetividades enquanto processos contínuos e ininterruptos que sujeitam os corpos e os comportamentos (FOUCAULT, 2008), intermediados pelas práticas sociais e culturais, resta-nos 
compreender quais são estes procedimentos. Para tanto, compreender as práticas de sujeição do indivíduo requer não apenas a compreensão do fenômeno como um todo, mas também, sujeitar-se a estes processos para compreender a si mesmo na coletividade constituída, o que implica em trazer a fenomenologia enquanto método calcado na observação-participante ${ }^{10}$.

\section{Considerações finais}

Este trabalho buscou explorar algumas questões pertinentes e relevantes para se pensar acerca dos processos imersivos em jogos pervasivos, principalmente na subcategoria de jogo chamada de Alternate reality games. Temos como questão central a ideia de que tal gênero de jogo busca transbordar as fronteiras entre realidade e ficcionalidade, ao explorar nas suas produções transmidiáticas que compõem a narrativa uma peculiar estética do real. Defendemos que esta estética do real, utilizada como recurso nos suportes midiáticos explorados neste gênero de jogo, seja o elemento primordial para que os processos imersivos em jogos de realidade alternada ocorram. Tal estética utiliza-se de códigos hermenêuticos ontológicos para que as fronteiras entre realidade e ficcionalidade sejam permeáveis.

Apesar de defender a estética do real como elemento primordial para os processos imersivos, este trabalho não exclui a existência de outros recursos que corroborem para a imersão neste gênero de game. Desta forma, defendemos que a imersão é alcançada através da utilização de diversos elementos do gameplay, como a narrativa, a interação entre personagens e jogadores, a alimentação das redes sociais pelos puppetsmasters, os níveis de dificuldade dos enigmas intercalados com puzzles menos complexos e fáceis de serem desvendados, entre outros.

10 Tal método foi adotado em trabalhos anteriores (OLIVEIRA, 2011). 
Levando em consideração que a imersão, de uma forma mais abrangente e não atendo-se apenas aos jogos de realidade alternada, é um fenômeno cognitivo individual que necessita de um investimento emocional e temporal do jogador, surge uma nova questão sobre o sujeito enquanto indivíduo pertencente a uma coletividade orgânica para o funcionamento dos ARG. Como a imersão é um processo individual, e como os ARG são um jogo essencialmente coletivo, a imersividade do jogador fica constantemente dependente da atuação dos outros membros da comunidade de ARG players.

Defendemos, ainda, a existência de elementos da subjetividade dos jogadores que não são inerentes ao ingame, porém são essenciais para que estimulem os jogadores a participarem da experiência. Tais elementos subjetivos são inerentes ao próprio ser humano, como o desejo de visibilidade e reconhecimento entre seus pares e uma necessidade de ficcionalização de si, como parte de uma revolução individualista (LIPOVETSKY; SERROY, 2009), porém ainda enraizados na interdependência pela coletividade, subentendidos tacitamente ao princípio da colaboratividade inerente à web 2.0.

A outra questão que atravessa este artigo é a de que os processos imersivos em jogos tradicionais são condicionados à performance do jogador em relação ao suporte onde o programa está sendo executado. Como nos jogos pervasivos não há a utilização de apenas um suporte, o investimento emocional é fragmentado pelos diversos canais explorados pelos ARG. Com isso, a imersão total (BROWN, CAIRNS, 2004) só é atingida através do fingimento, ou seja, do fenômeno TINAG, presente e necessário para a essencialidade deste gênero de jogo. Partindo do princípio de que este "efeito Pinóquio" é uma suspensão voluntária da descrença e uma criação ativa da crença, baseada nas definições teóricas de Jane McGonical e Janet Murray, este trabalho buscou compreender a relação aos processos de subjetivação dos quais novas configurações contemporâneas são delineadas. Mais do que suspensão voluntária da descrença, os efeitos cognitivos e psicológicos presentes nos live actions ocorrem involuntariamente, devido ao transbordamento de realidades e ficcionalidades. Inúmeras são as postagens de 


\begin{abstract}
jogadores que descrevem esse sentimento, como um "meio segundo"11 em que duvidaram da veracidade destas ações de campo, apontando este anseio como totalmente necessário para a experiência.
\end{abstract}

\title{
Rei Azul
}

haha Neto.

Isso mesmo Luiz, só precisa ser no começo.

Sei q muita gente acha qé pq somos (nem sei se falo em nome de mais alguém) exigentes, mas nem queremos muito, meio segundo de dúvida é o bastante para meses de emoçã̃o, falo por exeperiência própria.

Achar um blog escondido, desvendar uma chave, avançar uma informaçẫo, descobrir um perfil q faz parte da trama, enfim.

Achei um pedaço de um mapa do ZI no teatro José de Alencar.

Cara eu fui lá sabendo q era um ARG ué, fui lá 2 x pra achar. Sabia q ganharia um premio ao achar o mapinha.

Falei com a diretora, coma chefe da logística, descobri q a cantina antes era colada no palco, conheci o sr Tarzan que tinha apenas 1 olho (100\% verdade, o sr Tarzan (com rg e tudo) trabalha no teatro há décadas e tem apenas 1 olho devido a um acidente), vi as fotos do seu Muriçoca (antigo dono da cantina q ainda leva seu nome), vi as fotos dele com musas do teatro na parede, com artistas internacionais em roupas antigas, mas isso TUDO apesar de me deixar maluco quando penso, lembro, escrevo, ainda nẩo tinha sido nada, nada mesmo comparado ao q eu sentiria.

Na hora $q$ achei o pedaço de mapa enrolado em um barbante preso debaixo de uma escada, soltei ele no chẫo de medo, pavor, supresa, felicidade, tudo misturado. Direto no cortex central, nẫo consegui firmar a mẫo.

Isso durou meio segundo no máximo, mas aquele meio segundo foi real, a emoçẫo foi real, nẫo foi como ler um excelente livro, ver um excelente filme, durante meio segundo eu era o livro, eu era o filme.

Só isso, só meio segundo já basta.

Figura 1 : Retirada de uma entrevista aberta realizada em uma comunidade do Orkut do game Os Guardiões, em 2009.

Apesar dos jogadores dominarem a decodificação dos elementos sígnicos que os permitem identificar o real do ficcional, a estética do real explorada neste gênero de jogo, seja da narrativa ou das imagens audiovisuais e digitais, propicia esta dúvida temporária e efêmera. Tal micro-suspensão involuntária é o que norteia o desejo do jogador por tal experiência.

11 Disponívelem: http://www.orkut.com.br/Main \#CommMsgs?cmm=92019302\&tid=5362364083431724913\&na=4\&nst= 


\section{Referências}

ARSENAULT, D. "Dark Waters: spotlight on immersion". Anais do Game on North America International Conference. Eurosis-ETI, 2005.

BARTHES, R. S/Z. Rio de Janeiro: Nova Fronteira, 1992. . "O efeito de real". In: O rumor da língua. São Paulo: Martins Fontes, 2004.

BROWN, E; CAIRNS, P. "A grounded investigation of game immersion". In: Extended Abstracts on Human Factors in Computing Systems. New York: ACM, 2004.

COUCHOT, E. A tecnologia na arte: da fotografia à realidade virtual. Trad. Sandra Rey. Porto Alegre: Editora da UFRGS, 2003.

DELEUZE, G. Conversações. 1972-1990. Rio de Janeiro: Ed. 34, 1992.

ECO, U. Viagem na irrealidade cotidiana. Rio de Janeiro: Nova Fronteira, 1984.

ERMI, L; MÄYRÄ, F. "Fundamental components of gameplay experiences: analyzing immersion". Anais da conferência Changing Views - Digital Games Research Conference. Utrecht: Utrecht University, 2005.

FELDMAN, I. "O apelo realista". In: Revista FAMECOS, Porto Alegre, n.36, ago. 2008.

FERREIRA, E; FALCÃO, T. "Through the looking glass: weavings between the magic circle and immersive process in video games". Digital Games Research Association 2009 Conference. Breaking New Ground: Innovation in Games, Play, Practice and Theory. UK: London, 2009.

; OLIVEIRA, T. "Som, imersão e jogos eletrônicos: um estudo empírico". Anais do X Simpósio Brasileiro de Games e Entretenimento Digital - SBGames. Salvador: 2011.

FOUCAULT, M. Nascimento da biopolítica. Rio de Janeiro: Martins Fontes, 2008.

GUATTARI, F. Caosmose: um novo paradigma estético. São Paulo: Editora 34, 1992. 
HUIZINGA, J. Homo Ludens. São Paulo: Perspectiva, 1980.

JAGUARIBE, B. "Ficções do real: notas sobre as estéticas do realismo e pedagogias do olhar na América Latina contemporânea". Revista Ciberlegenda, n. 23, v. 1, 2010.

JUUL, J. "The game, the player, the world: looking for a heart of gameness". Anais da Congerência Level Up - Digital Games Research Conference. Utrecht: Utrecht University, 2003.

LIPOVETSKY, G; SERROY, Jean. A tela global: global, mídias culturais e cinema na era hipermoderna. Porto Alegre: Ed. Sulina, 2009.

LONG, G. Transmedia storytelling: business, aesthetics and production at the Jim Henson Company. Dissertação (mestrado). Massachusetts Institute of Technology, Massachesetts, 2000.

MACHADO, A. "Regimes de Imersão e Modos de Agenciamento". Anais do XXV Congresso Brasileiro de Ciências da Comunicação. INTERCOM - Sociedade Brasileira de Estudos Interdisciplinares da Comunicação. Salvador: 2002.

MATURANA R., H; VARELA, F. J. Autopoiesi e cognizione: la realizzazione del vivente. Veneza: Marsilio Editori, 1992.

MCGONIGAL, J. This might be a game: ubiquitous play and performance at the turn of the twenty-first century. Tese (doutorado). University of California, Berkeley, 2006.

. "This is not a game: immersive aesthetics and collective play". Anais da 5th International Digital Arts and Culture Conference. Melbourne, 2003.

MONTOLA, M; STENROS, J; WAERN, A. Pervasive games: theory and design. Oxford: Morgan Kaufmann editor, 2009.

MURRAY, J. Hamlet no Holodeck: o futuro da narrativa no ciberespaço. São Paulo: Itaú cultural; UNESP, 2003.

NIEUWDORP, E. "The pervasive interface: tracing the magic circle". Changing views Digital games research conference. Anais. Utrecht: Utrecht University, 2005. 
OLIVEIRA, T. Isto não é um jogo: configurações cognitivas no processo de se jogar um Alternate Reality Game. Dissertação (mestrado). Universidade Federal Fluminense, Niterói, 2011.

; ANDRADE, L. A. Um jogo de realidades e ficcionalidades. Revista Ciberlegenda, Rio de Janeiro, no 22, ano 12. Junho de 2010. Estação Transmídia. Disponível em: http://www.proppi.uff.br/ciberlegenda/um-jogo-de-realidades-e-ficcionalidades.

PROVOST, D. Metafiction and Web Based Story Telling. Parson School, 2008. Disponível em: http://a.parsons.edu/ provd139/thesis/papers/dprovost_metafiction.pdf.

RYAN , M. L. Narrative as virtual reality: immersion and interactivity in literature and electronic media. Baltimore: Johns Hopkins University Press, 2001.

SALEN, K. e ZIMMERMAN, Eric. Rules of play: game design fundamentals. Cambridge: MIT Press, 2003.

SIBILIA, P. O show do eu: a intimidade como espetáculo. Rio de Janeiro: Nova Fronteira, 2008. 